EXTENDED REPORT

\title{
Raised granzyme B levels are associated with erosions in patients with early rheumatoid factor positive rheumatoid arthritis
}

\author{
R Goldbach-Mansky, S Suson, R Wesley, C E Hack, H S El-Gabalawy, P P Tak
}

Ann Rheum Dis 2005;64:715-721. doi: 10.1136/ard.2003.007039

See end of article for authors' affiliations

Correspondence to: Dr Paul P Tak, Division of Clinical Immunology and Rheumatology, Academic Medical Centre/University of Amsterdam, F4-218 PO Box 22700, 1100 DE Amsterdam, Netherlands; p.p.tak@amc.uva.n

Accepted

18 September 2004

Published Online first

7 October 2004

\begin{abstract}
Background: Raised granzyme B in serum and synovium of patients with rheumatoid arthritis suggests a role for cytotoxic $T$ cells and natural killer cells in the pathogenesis of this disease.

Objective: To evaluate serum granzyme $B$ in patients with early arthritis and correlate it with specific diagnosis and clinical indices of disease severity.

Methods: 257 patients with inflammatory arthritis for less than one year (46\% rheumatoid arthritis, 17\% spondyloarthropathy, 37\% undifferentiated arthritis) had a prospective clinical, serological, and radiographic evaluation. Granzyme B was measured in initial sera by ELISA. Patients were HLA typed for DR alleles using sequence specific primers. A logistic regression model was used to evaluate the potential prognostic value of serum granzyme B in predicting radiographic erosions after one year of follow up.

Results: Granzyme B values were similar in rheumatoid arthritis, spondyloarthropathy, and undifferentiated arthritis. Concentrations were higher in rheumatoid factor (RF) positive patients than in RF negative patients (mean (SD): $3.15(0.92) \vee 2.89(0.71) \mathrm{pg} / \mathrm{ml} ; \mathrm{p}<0.05)$. After one year, erosions were present in $30 \%$ of patients in the overall cohort, and in $44 \%$ of patients with rheumatoid arthritis. In the entire cohort, serum granzyme B did not predict erosions independently. However, high granzyme B was an independent predictor of early erosions in patients with RF positive rheumatoid arthritis lodds ratio $=4.83(95 \%$ confidence interval, 1.13 to 20.59$))(p<0.05)$.

Conclusions: Granzyme B may be a useful prognostic marker in early rheumatoid arthritis and may provide important clues to the pathogenesis of this disease.
\end{abstract}

$\mathrm{R}$ heumatoid arthritis is a chronic inflammatory disorder affecting synovial tissue in multiple joints. Chronic synovial inflammation is found in early rheumatoid arthritis, ${ }^{1}$ as asymptomatic synovitis precedes the development of signs and symptoms of arthritis. ${ }^{2}$ Thus, early rheumatoid synovial tissue is characterised by mononuclear cell infiltration ${ }^{13}$ as well as by increased expression of adhesion molecules, ${ }^{4}$ cytokines, ${ }^{15}$ and matrix metalloproteinases. $^{67}$

Early rheumatoid synovial tissue is infiltrated by cytotoxic cells, possessing specialised granules which contain perforin and a group of serine proteinases termed granzymes. Previous cross sectional studies have shown a specific increase in the number of granzyme positive cytotoxic cells in rheumatoid synovial tissue compared with reactive arthritis $^{8}$ and osteoarthritis. ${ }^{910}$ In addition, granzymes are expressed by natural killer cells and cytotoxic lymphocytes in the synovial fluid of patients with rheumatoid arthritis. ${ }^{11}{ }^{12}$ Taken together, these studies suggest that there is increased expression of intracellular granzymes in the synovial compartment.

Granzymes may be released from cells during degranulation of cytotoxic cells, leading to their presence in body fluids. ${ }^{13}{ }^{14}$ Of note, measurements of soluble granzymes have shown that there is a marked increase in granzyme $\mathrm{B}$ concentrations in plasma and synovial fluid of patients with established rheumatoid arthritis compared with disease controls. ${ }^{15}$ As granzyme B might play a pathogenic role in the process of joint damage in rheumatoid arthritis, ${ }^{16}{ }^{17}$ we wanted to determine whether measurement of soluble granzymes could be used as a prognostic marker in patients with early arthritis to predict the development of erosive disease.

\section{METHODS}

\section{Clinical assessment}

Two hundred and fifty seven patients were recruited from local practising rheumatologists into an early synovitis study at the NIAMS (protocol 94-AR-194). The study was approved by the local medical ethics committee and patients gave their written informed consent.

To qualify for entry, patients had to have persistent arthritis in at least one peripheral joint for more than six weeks. Total disease duration was less than one year in the majority of patients, although in a few the waxing and waning nature of the symptoms precluded an accurate assessment of duration. Patients with traumatic, septic, and crystal induced arthritis were excluded.

Patients were evaluated clinically, serologically, and radiographically at the initial visit and at six weeks, six months, and one year. The total number of affected joints was calculated on the basis of the presence of either tenderness or swelling in a joint, as previously described. ${ }^{18}$ Anteroposterior and lateral radiographs of the hands and feet and $x$ rays of any other clinically involved joints were obtained at the initial visit (if such films were not obtained within the

Abbreviations: ACR, American College of Rheumatology; CTL, cytotoxic T lymphocyte; DMARD, disease modifying antirheumatic drug; ESSG, European Spondylarthropathy Study Group; NIAMS, National Institute of Arthritis and Musculoskeletal and Skin Diseases; PCR-SSP polymerase chain reaction-sequence specific primer; RF, rheumatoid factor; SpA, spondylarthropathy; UA, undifferentiated arthritis 
Table 1 Patient description of demographic, clinical, and treatment characteristics

\begin{tabular}{|c|c|c|c|c|}
\hline & $\begin{array}{l}\text { All patients } \\
\text { ( } n=257)\end{array}$ & RA $(n=119)$ & $\mathrm{SpA}(\mathrm{n}=43)$ & UA (n= 95) \\
\hline Age (years) & $43(13)$ & $46(13)^{*}$ & $37(11)$ & 41 (13) \\
\hline Female & $167(65 \%)$ & $77(65 \%)$ & $27(63 \%)$ & $63(65 \%)$ \\
\hline White & $218(85 \%)$ & $98(82 \%)$ & $43(100 \%)^{*}$ & $77(81 \%)$ \\
\hline Symptom duration (weeks) & $33(31)$ & $32(23)$ & $31(36)$ & 35 (37) \\
\hline TJC & $12(12)$ & 20 (12)* & $5(10)$ & $5(5)$ \\
\hline SJC & $8(9)$ & $14(9)^{*}$ & $2(2)$ & $2(3)$ \\
\hline $\operatorname{ESR}(\mathrm{mm} / \mathrm{h})$ & $39(30)$ & $44(30)^{*}$ & $40(30)$ & $33(30)$ \\
\hline$C$ reactive protein $(\mathrm{mg} / \mathrm{dl})$ & $1.8(2.3)$ & $2.0(2.2)^{*}$ & $2.0(3.2)^{*}$ & $1.4(1.9)$ \\
\hline $\mathrm{RF}>20$ & $95(37 \%)$ & $78(66 \%)^{*}$ & $2(5 \%)$ & $15(16 \%)$ \\
\hline Shared epitope & $115(45 \%)$ & $67(56 \%)^{*}$ & $18(42 \%)$ & $30(32 \%)$ \\
\hline Radiographic erosions $\dagger$ & $57(30 \%) \dagger$ & $44(44 \%) \dagger^{*}$ & $3(12 \%)+$ & $10(16 \%) \dagger$ \\
\hline Prednisone at 1 year & $52(20 \%)$ & $41(34 \%)^{*}$ & $3(34 \%)$ & $8(16 \%)$ \\
\hline Prednisone initially & $61(23 \%)$ & $40(34 \%)$ & $11(25 \%)$ & $9(10 \%)$ \\
\hline DMARD at 1 year & $100(39 \%)$ & $71(60 \%)^{*}$ & $10(23 \%)$ & $19(20 \%)$ \\
\hline DMARD initially & $60(23 \%)$ & $41(34 \%)^{*}$ & $8(19 \%)$ & $11(12 \%)$ \\
\hline \multicolumn{5}{|c|}{$\begin{array}{l}\text { Values are mean (SD) or } n(\%) \text {. } \\
\text { *Significant values for comparisons between groups in bold. } \\
\text { †A complete set of radiographs was only available for } 188 \text { patients ( } 100 \mathrm{RA}, 26 \mathrm{SpA}, 62 \mathrm{UA}) \text {. } \\
\text { DMARD, disease modifying anti-rheumatic drug; ESR, erythrocyte sedimentation rate; RA, rheumatoid arthritis; RF, } \\
\text { rheumatoid factor; SJC, swollen joint count; SpA, spondylarthropathy; TJC, total joint count; UA, undifferentiated } \\
\text { arthritis. }\end{array}$} \\
\hline
\end{tabular}

previous three months) and at the one year follow up visit. All radiographs were evaluated for the presence of erosions by an experienced musculoskeletal radiologist. Erosions were defined as the presence of radiographic erosions of any involved joint, detected on either initial or one year follow up radiographs. A complete set of radiographs was only available for 188 patients; these patients were included in the logistic regression analysis. In this subset of patients with a complete set of radiographs, 100 had rheumatoid arthritis, 26 had spondyloarthropathy, and 62 had undifferentiated arthritis. A subset analysis of demographic, serological, and treatment variables in the patients with a complete set of radiographs did not differ significantly from the total patient population (data not shown). Routine laboratory data were obtained on each visit, including an evaluation of acute phase reactants. The American College of Rheumatology (ACR) criteria for rheumatoid arthritis ${ }^{19}$ and the ESSG criteria ${ }^{20}$ were applied to each patient. Patients who did not fulfil either set of criteria were classified as having an undifferentiated arthropathy.

\section{Serological evaluation}

Granzyme B concentrations were measured in the initial patient sera using a recently developed enzyme linked immunosorbent assay (ELISA) technique. ${ }^{14}{ }^{15}$ Previously, we compared levels of soluble granzymes in serum and EDTA plasma from normal healthy individuals and found that the levels in these paired samples were similar (Hack CE et al, unpublished observations). Hence, artificial release during blood clotting from activated cytotoxic T lymphocytes does not affect the results.

Rheumatoid factor (RF) was measured by nephelometry; a value of $>20 \mathrm{IU} / \mathrm{ml}$ was considered positive.

\section{HLA typing}

Patients were HLA-DR typed by the molecular PCR-SSP method using standard sequence specific primers. ${ }^{18}$

\section{Statistical analysis}

Statistical analysis was carried out using SAS for the logistic regression model and EpiInfo statistical software for parametric and non-parametric comparisons between groups (Center for Disease Control, Atlanta: http://www.cdc.gov/ epiinfo).

Non-parametric measures, medians, and interquartile ranges were used because of the non-normality of the data.

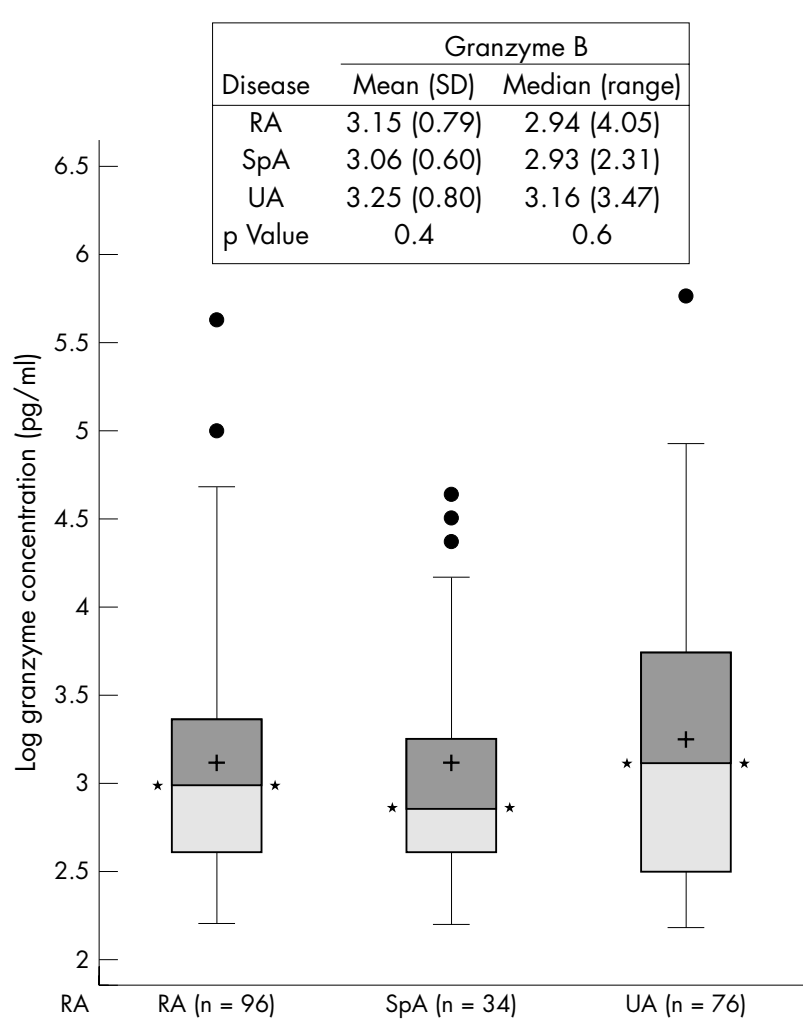

Figure 1 Box and whisker plots: boxes signify 25th and 75th centiles, whiskers 10th and 90th centiles, crosses are means, dots are outliers. Comparisons were made between disease groups. Means and medians are given, as well as $p$ values for parametric (ANOVA) and nonparametric (Kruskal-Wallis) analyses. Granzyme B values (for patients with levels $>10 \mathrm{pg} / \mathrm{ml}$ ) are computed as log granzyme concentrations in $\mathrm{pg} / \mathrm{ml}$. RA, rheumatoid arthritis; SpA, spondylarthropathy; UA, undifferentiated arthritis.

The distribution of the data was exponential so levels of granzyme B were logarithmically transformed to enable the use of linear statistics. Results were computed as the logarithm of the concentration in $\mathrm{pg} / \mathrm{ml}$. The outcome variable, erosions at one year, was dichotomous and qualitatively examined the presence or absence of radiographic erosions of the hands and feet or other clinically 
involved joints at one year. Univariate analysis was done to test the relation of the baseline variables examined to the outcome variable. Granzyme levels were either used as continuous variables or were transformed into categorical variables. As no control group data were available, a median value of $30 \mathrm{pg} / \mathrm{ml}$ for the whole cohort was used as a cut off for high and low levels of granzyme B.

A backward stepwise logistic regression model setting the retention criterion to $\mathrm{p}=0.1$ was used to evaluate the potential prognostic value of granzyme $\mathrm{B}$ in predicting radiographic erosions at one year. Independent variables that showed an association with the outcome variable in the univariate analysis were used in the model and included: age, sex, RF, shared epitope, erythrocyte sedimentation rate (ESR), total joint count, swollen joint count, and treatment with prednisone at study entry. Results of the logistic regression model are reported in the logit form and significant associations of these covariates with the development of erosions at one year are expressed as log odds with 95\% confidence intervals (CI). Patient groups were compared using analysis of variance (ANOVA) or the Kruskal-Wallis test for continuous variables, and the $\chi^{2}$ or Fisher exact test for proportions.

\section{RESULTS}

Of the 257 patients with arthritis of recent onset in the cohort, 119 (46\%) met ACR criteria for rheumatoid arthritis and $66 \%$ of these patients were RF positive. The demographic and clinical data on this patient cohort are given in table 1. Radiographic erosions were either present at entry or developed during the year of follow up. Of the patients with rheumatoid arthritis $44 \%$ had erosions at the one year visit. In comparison, only $12 \%$ and $16 \%$ of patients with either spondyloarthropathy or undifferentiated arthritis, respectively, had radiographic erosions at one year $(p<0.0001)$.

\section{Serum granzyme B in initial samples}

Figure 1 shows granzyme B concentrations in the serum obtained from all patients at the initial visit to the NIH. No significant difference in the mean serum granzyme B was detected in patients with either rheumatoid arthritis, spondyloarthropathy, or undifferentiated arthritis (mean (SD): $3.15(0.79), 3.06(0.6)$, and $3.25 \quad(0.8)$ pg/ml, respectively (NS)). However, significantly more RF positive patients (all arthropathies) had raised granzyme B concentrations compared with RF negative patients (29\% v 20\%, $\mathrm{p}<0.05$ ) (table 2), and mean concentrations of granzyme $B$ were higher in RF positive patients (3.15 (0.92) $v 2.89$ (0.71) $\mathrm{pg} / \mathrm{ml} ; \mathrm{p}=0.012$ ) (fig $2 \mathrm{~A}$ ). The difference in concentrations was further increased when RF positive patients with rheumatoid arthritis were compared with RF negative patients with rheumatoid arthritis (3.26 (0.85) v 2.89 (0.61) $\mathrm{pg} / \mathrm{ml} ; \mathrm{p}=0.026$ ) (fig $2 \mathrm{~B}$ ).

Table 2 Patients positive for granzyme B

\begin{tabular}{ll}
\hline Disease group & Granzyme B $>\mathbf{3 0} \mathbf{~ p g} / \mathbf{m l}(\mathbf{n}(\%))$ \\
\hline RF+ arthritis $(n=95)$ & $28(29)$ \\
RF- arthritis $(n=162)$ & $32(20)$ \\
$p$ Value & 0.049 \\
& $19(24)$ \\
RF+ RA $(n=78)$ & $5(12)$ \\
RF- RA $(n=41)$ & 0.089 \\
p Value &
\end{tabular}

RA, rheumatoid arthritis; RF+, rheumatoid factor positive; RF-, rheumatoid factor negative.
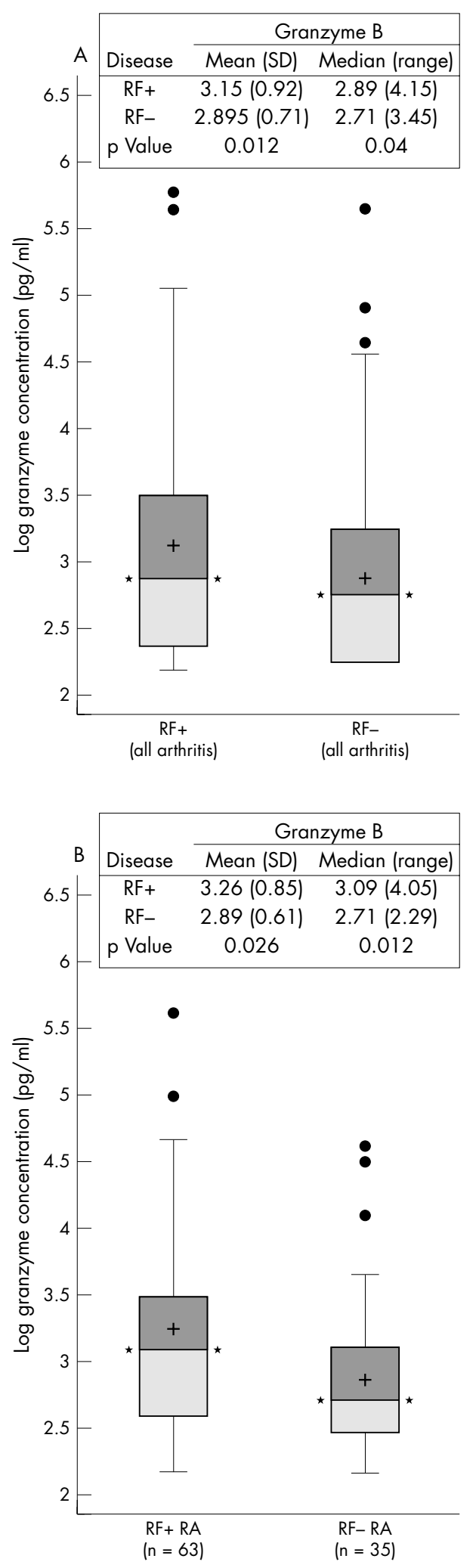

Figure 2 (A) Comparison of log granzyme $B$ concentrations between $\mathrm{RF}+$ and RF- cases (all arthropathies). (B) Comparison of log granzyme $\mathrm{B}$ concentrations between RF+ and RF - cases (rheumatoid arthritis cases only). Box and whisker plots: boxes signify 25th and 75th centiles, whiskers 10th and 90th centiles, crosses are means, dots are outliers. Comparisons were made between disease groups. Means and medians are given, as well as $p$ values for parametric (ANOVA) and nonparametric (Kruskall-Wallis) analyses. Granzyme B values (for patients with levels $>10$ ) are computed as log granzyme concentrations in pg/ $\mathrm{ml}$. RA, rheumatoid arthritis; RF+, rheumatoid factor positive; RF-, rheumatoid factor negative. 


\section{Correlation between granzyme B and markers of disease activity}

To obtain a measure of the degree of association between serological and genetic factors included in a model to predict early erosions, we examined the degree of correlation between granzyme B concentrations and markers of disease severity (table 3 ). The correlation between $\mathrm{RF}$ and the granzyme B concentration was $r=0.17 \quad(\mathrm{p}<0.05)$ when values greater than $10 \mathrm{pg} / \mathrm{ml}$ were used. No correlation was observed between granzyme B with markers of inflammation (ESR or C reactive protein), the number of swollen joints, or the total number of joints involved, which may be explained by the fact that stimuli for degranulation of cytotoxic $\mathrm{T}$ cells or natural killer (NK) cells are not necessarily the same as those for the inflammatory response in rheumatoid arthritis. High granzyme B concentrations were not significantly associated with the shared epitope (data not shown).

\section{Association of granzyme B concentrations with the presence of radiographic erosions}

Table 4 summarises results obtained from univariate analysis examining baseline variables that have either been shown in previous studies to be associated with erosions at one year ${ }^{21-25}$ or were selected on the basis of clinical suspicion (such as previous treatment with steroids or disease modifying antirheumatic drugs (DMARDs)). Consistent with other studies, predictors of erosions included shared epitope, RF, and swollen joints. When all patients with early inflammatory synovitis in our cohort $(n=188)$ were evaluated, the presence of at least one copy of the shared epitope $(\mathrm{p}<0.005)$ and the presence of RF $(p<0.01)$ were the strongest predictors of erosions at one year in univariate analysis. The total number of involved joints and the swollen joint count were also significantly associated with the radiological outcome. When a subset of patients with rheumatoid arthritis $(\mathrm{n}=98)$ who fulfilled ACR criteria were evaluated, or when only patients with RF positive rheumatoid arthritis $(n=62)$ were evaluated, high granzyme B concentrations were also associated with the presence of erosive disease $(\mathrm{p}<0.05$ in both instances).

We subsequently used a logistic regression analysis to screen whether granzyme B was an independent predictor of the presence of radiographic erosions at one year. The results from this analysis are shown in table 5 . The statistical model was examined in all patients with adequate radiographic data $(\mathrm{n}=188)$, in all patients with rheumatoid arthritis $(\mathrm{n}=98)$, and in the subset of patients with RF+ rheumatoid arthritis $(n=62)$. Results are expressed as log odds with 95\% CI. In the model incorporating all patients, radiographic erosions at one year were predicted by the presence of at least one copy of the shared epitope (odds ratio $(\mathrm{OR})=2.27$ (95\% CI, 1.14 to $4.50), \mathrm{p}<0.05)$. Other predictors were $\mathrm{RF}(\mathrm{OR}=2.22$ ( 1.10 to $4.50), \mathrm{p}<0.05), \mathrm{C}$ reactive protein $(\mathrm{OR}=1.15$ (1.01 to 1.31$)$,

Table 3 Correlation of markers of disease activity with granzyme B concentrations in patients with rheumatoid arthritis only

\begin{tabular}{lllllc}
\hline Variable & $\begin{array}{l}\text { ESR } \\
(\mathbf{m m} / \mathbf{h})\end{array}$ & $\begin{array}{l}\text { CRP } \\
(\mathbf{m g} / \mathrm{dl})\end{array}$ & TJC & SJC & $\begin{array}{l}\text { Granzyme B } \\
(\mathrm{pg} / \mathbf{m l})\end{array}$ \\
\hline RF & $\mathbf{0 . 1 6 ^ { * }}$ & 0.08 & $\mathbf{0 . 2 7 \dagger}$ & $\mathbf{0 . 2 5 ^ { * }}$ & $\mathbf{0 . 1 7 ^ { * }}$ \\
ESR & & $0.66 \dagger$ & $0.19^{*}$ & $0.26 \dagger$ & -0.01 \\
CRP & & & $0.12^{*}$ & $0.18^{*}$ & 0.02 \\
TJC & & & & $0.85 \dagger$ & 0.00 \\
SJC & & & & & -0.05 \\
\hline
\end{tabular}

Pearson correlations between the different variable are shown: ${ }^{*} \mathrm{p}<0.05$, $\uparrow \mathrm{p}<0.0001$.

$\mathrm{CRP}, \mathrm{C}$ reactive protein; $\mathrm{ESR}$, erythrocyte sedimentation rate; $R F$, rheumatoid factor; SJC, swollen joint count; TJC, total joint count.

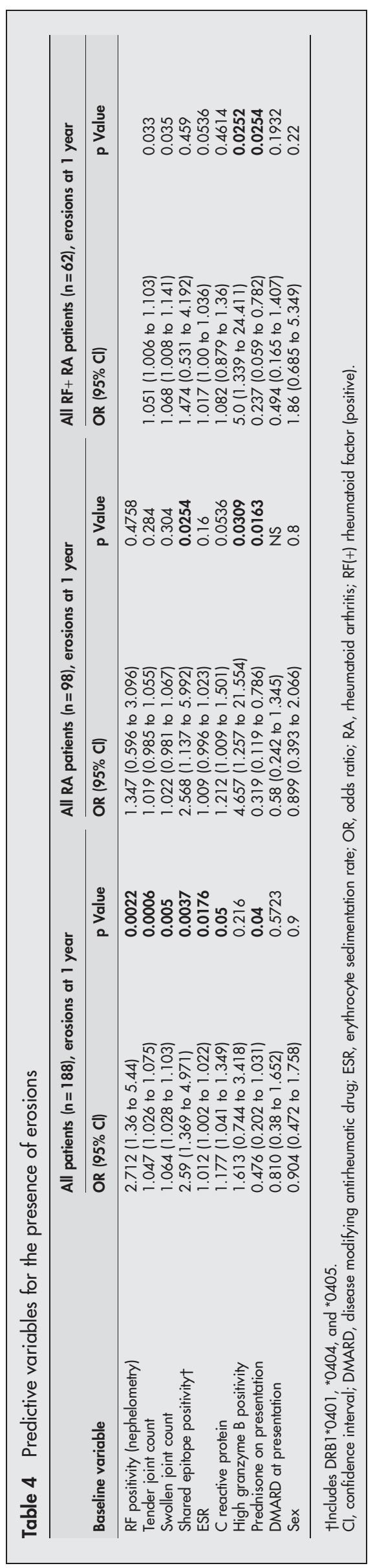




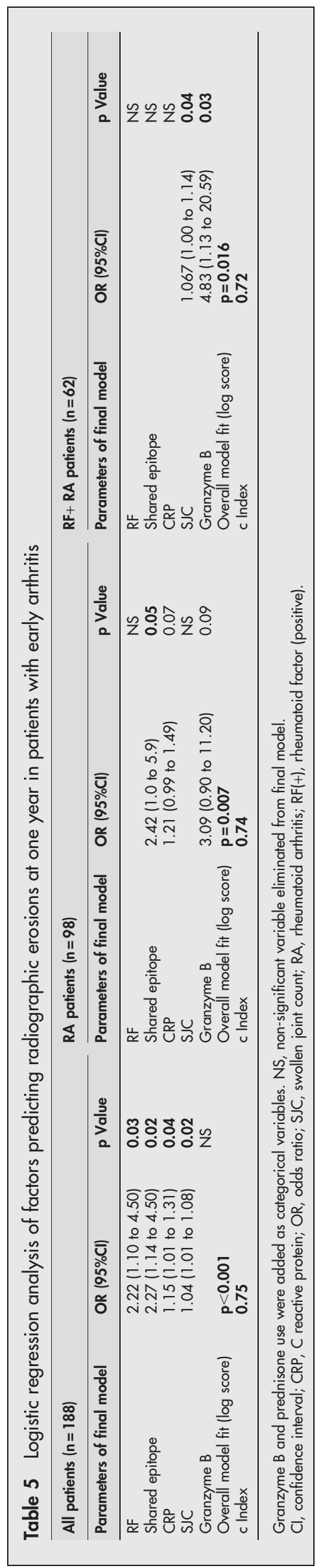

$\mathrm{p}<0.05)$, and swollen joint count ( $\mathrm{OR}=1.04$ ( 1.01 to 1.08$)$; $\mathrm{p}<0.05$ ). In the model including all patients, granzyme $B$ did not contribute significantly to the prediction of erosions over genetic and clinical risk factors ( $\mathrm{OR}=1.5(0.62$ to 3.46$)$, NS).

When the model was reduced to only include RF positive patients with rheumatoid arthritis, granzyme $\mathrm{B}$ was the strongest predictor of erosions with $\mathrm{OR}=4.83$ ( 1.13 to 20.59) $(\mathrm{p}<0.05)$, indicating that granzyme $\mathrm{B}$ is an independent predictor of erosive disease in this group of patients. The swollen joint count also seemed to predict erosions in this patient group (OR=1.07 ( 1.00 to 1.14$) ; \mathrm{p}=0.04)$.

\section{DISCUSSION}

Previous studies have shown that increases in granzyme B levels are more marked in the serum, synovial fluid, and synovial tissue of patients with rheumatoid arthritis than in those with osteoarthritis or reactive arthritis. ${ }^{8-10}{ }^{15}$ However, these studies have been cross sectional in nature and the patient populations examined were not appropriate to evaluate the significance of granzyme levels prospectively. We therefore explored the diagnostic and prognostic value of serum granzyme $\mathrm{B}$ in a cohort of patients with a diverse spectrum of early inflammatory arthritides of less than one year's duration. Our findings indicate that granzyme B concentrations are significantly higher in RF+ rheumatoid arthritis than in RF- rheumatoid arthritis, spondyloarthropathy, or undifferentiated arthritis.

This early arthritis cohort has been partially characterised previously, and includes patients with inflammatory arthritis that persisted for more than six weeks, excluding patients with osteoarthritis, septic arthritis, and crystal induced arthritis. ${ }^{18}$ The inclusion of all patients with an inflammatory arthropathy involving at least one swollen joint eliminates the bias in the study population that would occur if only those patients who fulfilled the ACR criteria for rheumatoid arthritis were included. Although $78 \%$ of our cohort with evidence of radiographic damage at one year fulfilled ACR criteria for rheumatoid arthritis at study entry, $22 \%$ of those with evidence of radiographic damage did not. These would have been excluded from the analysis unnecessarily. In most patients methotrexate was the initial DMARD.

The origin of the increase in serum granzyme in patients with rheumatoid arthritis is not fully known. Granzymes are constitutively expressed in natural killer (NK) cells, $\gamma \delta^{+}$ $\mathrm{T}$ cells, and most CD8+ cytotoxic T lymphocytes (CTL); they are induced in activated $\mathrm{T}$ lymphocytes and in a smaller proportion of CD4+ T cells. ${ }^{26}$ Many of the granzyme positive cells in the synovium are NK cells. ${ }^{9}$ A smaller number are CD8+ T cells, ${ }^{927}$ and CD4+ CD28- T lymphocytes. ${ }^{28}$ The presence of an increased number of granzyme positive cells in the synovium of patients with rheumatoid arthritis ${ }^{8-10}$ and the tendency for there to be higher levels of granzyme B in the synovial compartment than in the serum $^{15}$ have suggested that the rise in serum granzyme B may originate from extracellular release in the inflamed joint.

Granzyme B is a serine protease and its principal function is to induce death of virus infected and other potentially harmful cells. ${ }^{29}$ It is released by exocytosis and taken by receptor mediated endocytosis into the cytoplasm of the target cell, ${ }^{30}$ where it can directly activate several procaspases, cleave downstream caspase substrates including the inhibitor of caspase activated DNase, and thus contribute to DNA fragmentation and programmed cell death of the target cells. ${ }^{31-33}$ During the induction of apoptotic cell death, extracellular granzyme $\mathrm{B}$ which is not taken up by the receptor may be released and enter the circulation. Alternatively, granzyme release from NK cells and CD8+ T cells can also be triggered by chemokines. ${ }^{34}$ Many of the chemokines capable of inducing granzyme release spontaneously 
have been shown to be upregulated in synovial tissue in patients with rheumatoid arthritis. ${ }^{35} 36$

Increases of serum granzyme B are also seen during acute viral infections. ${ }^{14}$ Interestingly, oligoclonal expansions of virus specific CD8+ CTLs in the synovial compartment have suggested a possible role for viral infections in the aetiology of rheumatoid arthritis. ${ }^{37}{ }^{38}$ However, extensive evaluations of serum and synovial tissue failed to provide convincing evidence for a specific microbial infection in patients with rheumatoid arthritis. ${ }^{39}{ }^{40}$ The accumulation of these cells could reflect in part chemokine driven recruitment of memory cells rather than $\mathrm{T}$ cell expansion specific for expression of antigen in the synovium. ${ }^{41}$ In addition, granzyme B expression in NK cells could be upregulated by immune complexes and cytokines that are present in the synovial compartment, including interleukin (IL) 2, IL12, IL15, and IL18. ${ }^{42-44}$

Although in vivo evidence for the contribution of granzyme $\mathrm{B}$ to the inflammatory and destructive process in rheumatoid arthritis is currently lacking, it has been suggested that extracellularly released granzyme B may be involved in joint damage directly. In vitro studies have shown that granzyme $\mathrm{B}$ has enzymatic activity for the selective cleavage of aggrecan proteoglycans from cultured cartilage matrix and whole cartilage explants. ${ }^{16}{ }^{17}$ Furthermore, granzymes are important mediators of apoptosis, and might mediate cartilage destruction by the induction of apoptosis in chondrocytes. The presence of granzyme B positive cells in the synovium at the cartilage invading front suggests that extracellular granzyme B may work in concert with other proteolytic processes to contribute to cartilage loss and joint damage. This notion is supported by a recent study showing a relation between the number of granzyme B+ cytotoxic cells in rheumatoid synovial tissue and the severity of joint damage at follow up. ${ }^{45}$

In the present study we observed a clear association between the presence of RF and the serum levels of granzyme B. Previous work has shown that the detection of extracellular granzyme B by ELISA used in the present study is not influenced by RF. ${ }^{15}$ Conceivably, the increase in granzyme B levels in patients with RF+ rheumatoid arthritis could be explained by activation of NK cells by $\mathrm{RF}^{46}$ On the other hand, NK cells may induce IgM RF synthesis by B cells. ${ }^{47}$

The elevation of granzyme B levels in patients with RF+ rheumatoid arthritis and its possible role in joint destruction have prompted us to examine the independent value of granzyme B in the prediction of erosive disease in this cohort. When the entire patient cohort was assessed, patients with erosions had significantly higher levels of granzyme B than those without erosions. When independent predictors of erosions were studied in the whole cohort in a logistic regression model, granzyme B did not add independently to the prediction of erosions. Consistent with other studies, ${ }^{48-52}$ the presence of the shared epitope and RF positivity were the most significant independent predictors of erosions at one year in addition to markers of inflammation and the number of swollen joints. Of interest, when only RF+ patients were included in the model, raised serum granzyme B levels and the number of swollen joints were the strongest independent predictors of radiographic erosions at one year. As our study was not designed to examine whether granzyme B levels changed over time or were useful for following disease progression or response to treatment, long term controlled interventional studies are necessary to address these issues.

Alternatively or in addition to the direct tissue destructive potential, granzyme B could play a role in the initiation and propagation of systemic autoimmunity; joint destruction may follow as a result of persistent immune activation in the joint. $^{53}$ Recently it has been shown that autoantigens targeted across a spectrum of autoimmune diseases are susceptible to efficient cleavage by granzyme B, generating unique epitopes that are not usually seen in other forms of apoptosis, including cleavage by caspases. Autoantibody responses to the epitopes at granzyme cleavage sites have been observed..$^{55}$ This has suggested that common biochemical events which may occur during granule induced cell death could be responsible for selecting self antigens for high titre autoantibody responses. Whether a similar role of granzyme B in the generation of articular autoantigens is involved in the subsequent production of rheumatoid arthritis specific autoantibodies is currently under investigation.

The data presented here show that raised granzyme B concentrations are found in patients with early RF positive arthritis. In addition, increased granzyme B levels are associated with the early development of radiographic erosions in RF positive rheumatoid arthritis. Whether granzyme B mediates joint damage directly through enzymatic cartilage degradation, as shown previously in vitro, or perpetuates ongoing autoimmune processes in the joint in susceptible individuals, or is simply a marker of other events needs further evaluation. Long term controlled interventional studies are necessary to validate whether granzyme B levels might be useful as a surrogate marker to follow radiographic joint damage and the response to treatment.

\section{ACKNOWLEDGEMENTS}

We thank Angela Wolbink who did the soluble granzyme assays and Drs Peter E Lipsky and Betty Diamond for their careful review of the manuscript, and we acknowledge the invaluable contributions of Marianna Crane and Drs Thurayya Arayssi, Jose Pando, Percio Gulko, Richard Siegel, Michael Froncek, Robert Ortmann, and the NIH fellows who helped to carry out the clinical evaluation of the patients.

\section{Authors' affiliations}

R Goldbach-Mansky, S Suson, R Wesley, Arthritis and Rheumatism Branch, National Institute of Arthritis and Musculoskeletal and Skin Diseases, National Institutes of Health, Bethesda, Maryland, USA

C E Hack, Sanquin Research at the Central Laboratory of the Netherlands Red Cross Blood Transfusion Service, Amsterdam, Netherlands

H S El-Gabalawy, Division of Rheumatology, University of Manitoba, Winnipeg, Manitoba, Canada

P P Tak, Division of Clinical Immunology and Rheumatology, Academic Medical Centre, University of Amsterdam, Netherlands

\section{REFERENCES}

1 Tak PP, Smeets TJM, Daha MR, Kluin PM, Meijers KAE, Brand R, et al. Analysis of the synovial cellular infiltrate in early rheumatoid synovial tissue in relation to local disease activity. Arthritis Rheum 1997;40:217-25.

2 Kraan MC, Versendaal H, Jonker M, Bresnihan B, Post W, 't Hart BA, et al. Asymptomatic synovitis precedes clinically manifest arthritis. Arthritis Rheum 1998;41:1481-8.

3 Baeten D, Demetter P, Cuvelier C, Van Den BF, Kruithof E, Van Damme N, et al. Comparative study of the synovial histology in rheumatoid arthritis, spondyloarthropathy, and osteoarthritis: influence of disease duration and activity. Ann Rheum Dis 2000;59:945-53.

4 Tak PP, Thurkow EW, Daha MR, Kluin PM, Smeets TJM, Meinders AE, et al. Expression of adhesion molecules in early rheumatoid synovial tissue. Clin Immunol Immunopathol 1995;77:236-42.

5 Muller-Ladner U, Judex M, Ballhorn W, Kullmann F, Distler O, Schlottmann K, et al. Activation of the IL-4 STAT pathway in rheumatoid synovium. J Immunol 2000;164:3894-901

6 Cunnane G, FitzGerald O, Hummel KM, Gay RE, Gay S, Bresnihan B. Collagenase, cathepsin $B$ and cathepsin $L$ gene expression in the synovial membrane of patients with early inflammatory arthritis. Rheumatology
1999;38:34-42.

7 Goldbach-Mansky R, Lee JM, Hoxworth JM, Smith D, Duray P, Schumacher HR, et al. Active synovial matrix metalloproteinase-2 is associated with radiographic erosions in patients with early synovitis. Arthritis Res 2000; http://arthritis-research.com/content/2/2/145/.

8 Smeets TJ, Dolhain RJ, Breedveld FC, Tak PP. Analysis of the cellular infiltrates and expression of cytokines in synovial tissue from patients with rheumatoid arthritis and reactive arthritis. J Pathol 1998;186:75-81.

9 Tak PP, Kummer JA, Hack CE, Daha MR, Smeets TJM, Erkelens GW, et al. Granzyme positive cytotoxic cells are specifically increased in early rheumatoid synovial tissue. Arthritis Rheum 1994;37:1735-43. 
10 Muller-Ladner U, Kriegsmann J, Tschopp J, Gay RE, Gay S. Demonstration of granzyme A and perforin messenger RNA in the synovium of patients with rheumatoid arthritis. Arthritis Rheum 1995;38:477-84.

11 Young LH, Joag SV, Lin PY, Luo SF, Zheng LM, Liu CC, et al. Expression of cytolytic mediators by synovial fluid lymphocytes in rheumatoid arthritis. Am J Pathol 1992;140:1261-8.

12 Griffiths GM, Alpert S, Lambert E, McGuire J, Weissman IL. Perforin and granzyme A expression identifying cytolytic lymphocytes in rheumatoid arthritis. Proc Natl Acad Sci USA 1992:89:549-53.

13 Takayama H, Trenn G, Humphrey W, Bluestone JA, Henkart PA, Sitkovsky MV. Antigen receptor-triggered secretion of a trypsin-type esterase from cytotoxic T lymphocytes. J Immunol 1987;138:566-9.

14 Spaeny-Dekking EHA, Hanna WL, Wolbink AM, Wever PC, Kummer JA, Swaak $A J G$, et al. Extracellular granzymes $A$ and $B$ in man: detection of native species during CTL responses in vitro and in vivo. $J$ Immunol 1998;160:3610-16

15 Tak PP, Spaeny-Dekking L, Kraan MC, Breedveld FC, Froelich CJ, Hack CE. The levels of soluble granzyme $A$ and $B$ are elevated in plasma and synovial fluid of patients with rheumatoid arthritis (RA). Clin Exp Immunol 1999; 116:366-70.

16 Froelich CJ, Zhang X, Turbov J, Hudig D, Winkler U, Hanna WL. Human granzyme $B$ degrades aggrecan proteoglycan in matrix synthesized by chondrocytes. J Immunol 1993;151:7161-71.

17 Ronday HK, van der Laan WH, Tak PP, De Roos JA, Bank RA, TeKoppele JM et al. Human granzyme B mediates cartilage proteoglycan degradation and is expressed at the invasive front of the synovium in rheumatoid arthritis. Rheumatology (Oxford) 2001;40:55-61.

18 El Gabalawy HS, Goldbach-Mansky R, Smith D, Arayssi T, Bale S, Gulko P, et al. Association of HLA alleles and clinical features in patients with synovitis of recent onset. Arthritis Rheum 1999:42:1696-705.

19 Arnett FC, Edworthy SM, Bloch DA, McShane DJ, Fries JF, Cooper NS, et al. The American Rheumatism Association 1987 revised criteria for the classification of rheumatoid arthritis. Arthritis Rheum 1988;31:315-24.

20 Dougados $M$, van der Linden SM, Juhlin R, Huiffeldt B, Amor B, Calin A, et al. The European Spondylarthropathy Study Group preliminary criteria for the classification of spondylarthropathy. Arthritis Rheum 1991;34:1218-27.

21 Brennan P, Harrison B, Barrett E, Chakravarty K, Scott D, Silman A, et al. A simple algorithm to predict the development of radiological erosions in patients with early rheumatoid arthritis: prospective cohort study. BMJ 1996;313:471-6.

22 Fex E, Jonsson K, Johnson U, Eberhardt K. Development of radiographic damage during the first 5-6 yr of rheumatoid arthritis. A prospective followup study of a Swedish cohort. Br J Rheumatol 1996:35:1 106-15.

23 Combe B, Dougados M, Goupille P, Cantagrel A, Eliaou JF, Sibilia J, et al. Prognostic factors for radiographic damage in early rheumatoid arthritis: a multiparameter prospective study. Arthritis Rheum 2001;44:1736-43.

24 Visser $\mathrm{H}$, le Cessie S, Vos K, Breedveld FC, Hazes JM. How to diagnose rheumatoid arthritis early: a prediction model for persistent (erosive) arthritis. Arthritis Rheum 2002;46:357-65

25 Lindqvist E, Jonsson K, Saxne T, Eberhardt K. Course of radiographic damage over 10 years in a cohort with early rheumatoid arthritis. Ann Rheum Dis 2003:62:611-16.

26 Liv CC, Persechini PM, Young JD. Perforin and lymphocyte-mediated cytolysis. Immunol Rev 1995; 146:145-75

27 Kummer JA, Tak PP, Brinkman B, Van Tilborg AAG, Kamp AM, Daha MR, et al. Expression of granzymes $A$ and $B$ in synovial tissue from patients with rheumatoid arthritis and osteoarthritis. Clin Immunol Immunopathol 1994;73:88-95.

28 Namekawa T, Wagner UG, Goronzy JJ, Weyand CM. Functional subsets of CD4 T cells in rheumatoid synovitis. Arthritis Rheum 1998;41:2108-116.

29 Trapani JA. Granzymes: a family of lymphocyte granule serine proteases. Genome Biol 2001 ; 2:REVIEWS3014.

30 Motyka B, Korbutt G, Pinkoski MJ, Heibein JA, Caputo A, Hobman M, et al. Mannose 6-phosphate/insulin-like growth factor II receptor is a death receptor for granzyme B during cytotoxic T cell-induced apoptosis. Cell 2000; 103:491-500

31 Duke RC, Persechini PM, Chang S, Liu CC, Cohen JJ, Young JD. Purified perforin induces target cell lysis but not DNA fragmentation. J Exp Med 1989; 170:1451-6.

32 Heusel JW, Wesselschmidt RL, Shresta S, Russell JH, Ley TJ. Cytotoxic lymphocytes require granzyme $B$ for the rapid induction of DNA fragmentation and apoptosis in allogeneic target cells. Cell 1994;76:977-87.

33 Thomas DA, Du C, Xu M, Wang X, Ley TJ. DFF $45 /$ ICAD can be directly processed by granzyme $B$ during the induction of apoptosis. Immunity 2000;12:621-32.
34 Loetscher P, Seitz M, Clark-Lewis I, Baggiolini M, Moser B. Activation of NK cells by $\mathrm{CC}$ chemokines. Chemotaxis, $\mathrm{Ca}^{2+}$ mobilization, and enzyme release. $\mathrm{J}$ Immunol 1996;156:322-7.

35 Ruth JH, Rottman JB, Katschke KJ, Qin S, Wu L, LaRosa G, et al. Selective lymphocyte chemokine receptor expression in the rheumatoid joint. Arthritis Rheum 2001;44:2750-60.

36 Haringman JJ, Ludikhuize J, Tak PP. Chemokines in joint disease: the key to inflammation? Ann Rheum Dis 2004;63:1 186-94.

37 Edinger JW, Bonneville M, Scotet E, Houssaint E, Schumacher HR, Posnett DN. EBV gene expression not altered in rheumatoid synovia despite the presence of EBV antigen-specific T cell clones. J Immunol 1999;162:3694-701.

38 Scotet E, Peyrat MA, Saulquin X, Retiere C, Couedel C, Davodeau F, et al. Frequent enrichment for CD8 T cells reactive against common herpes viruses in chronic inflammatory lesions: towards a reassessment of the physiopathological significance of $\mathrm{T}$ cell clonal expansions found in autoimmune inflammatory processes. Eur J Immunol 1999;29:973-85.

39 Stahl HD, Hubner B, Seid B, Liebert UG, van der Heijden IM, Willbrink B, et al. Detection of multiple viral DNA species in synovial tissue and fluid of patients with early arthritis. Ann Rheum Dis 2000;59:342-6.

40 van der Heijden IM, Wilbrink B, Tchetverikov I, Schrijver IA, Schouls LM, Hazenberg MP, et al. Presence of bacterial DNA and bacterial peptidoglycans in joints of patients with rheumatoid arthritis and other arthritides. Arthritis Rheum 2000:43:593-8.

41 Fazou C, Yang H, McMichael AJ, Callan MF. Epitope specificity of clonally expanded populations of CD8+ T cells found within the joints of patients with inflammatory arthritis. Arthritis Rheum 2001;44:2038-45.

42 Salcedo TW, Azzoni L, Wolf SF, Perussia B. Modulation of perforin and granzyme messenger RNA expression in human natural killer cells. J Immunol 1993;151:2511-20

43 Ye WG, Young JDE, Liu CC. Interleukin-15 induces the expression of mRNAs of cytolytic mediators and augments cytotoxic activities in primary murine lymphocytes. Cell Immunol 1996;174:54-62.

44 Yu Y, Hagihara M, Ando K, Gansuvd B, Matsuzawa H, Tsuchiya T, et al. Enhancement of human cord blood CD34+ cell-derived NK cell cytotoxicity by dendritic cells. J Immunol 2001;166:1590-600.

45 Kraan MC, Haringman JJ, Weedon H, Barg EC, Smith MD, Ahern MJ, et al T cells, fibroblast-like synoviocytes, and granzyme B+ cytotoxic cells are associated with joint damage in patients with recent onset rheumatoid arthritis. Ann Rheum Dis 2004;63:483-8.

46 Hendrich C, Kuipers JG, Kolanus W, Hammer M, Schmidt RE. Activation of $\mathrm{CD} 16+$ effector cells by rheumatoid factor complex. Role of natural killer cells in rheumatoid arthritis. Arthritis Rheum 1991:34:423-31.

47 Santiago Schwarz F, Kay C, Panagiotopoulos C, Carsons SE. Rheumatoid arthritis serum or synovial fluid and interleukin 2 abnormally expand natural killer-like cells that are potent stimulators of IgM rheumatoid factor. J Rheumatol 1992;19:223-8.

48 Nepom GT. The role of the DR4 shared epitope in selection and commitment of autoreactive T cells in rheumatoid arthritis. Rheum Dis Clin North Am 2001;27:305-15

49 Kaltenhauser S, Wagner U, Schuster E, Wassmuth R, Arnold S, Seidel W, et al. Immunogenetic markers and seropositivity predict radiological progression in early rheumatoid arthritis independent of disease activity. $J$ Rheumatol 2001;28:735-44.

50 Listing J, Rau R, Muller B, Alten R, Gromnica-lhle E, Hagemann D, et al. HLADRBl genes, rheumatoid factor, and elevated C-reactive protein: independent risk factors of radiographic progression in early rheumatoid arthritis. Berlin Collaborating Rheumatological Study Group. J Rheumatol 2000;27:2100-9.

51 van Zeben D, Hazes JM, Zwinderman AH, Vandenbroucke JP, Breedveld FC Factors predicting outcome of rheumatoid arthritis: results of a follow up study. $J$ Rheumatol 1993;20:1288-96.

52 van der Heijde DM, van Riel PL, van Leeuwen MA, 't Hof MA, van Rijswijk MH, van de Putte $L B$. Prognostic factors for radiographic damage and physical disability in early rheumatoid arthritis. A prospective follow-up study of 147 patients. Br J Rheumatol 1992;31:519-25.

53 Santamaria P. Effector lymphocytes in autoimmunity. Curr Opin Immunol 2001;13:663-9.

54 Casciola-Rosen L, Andrade F, Ulanet D, Wong WB, Rosen A. Cleavage by granzyme $B$ is strongly predictive of autoantigen status: implications for initiation of autoimmunity. J Exp Med 1999;190:815-26.

55 Rosen A, Casciolarosen L. Autoantigens as substrates for apoptotic proteases: implications for the pathogenesis of systemic autoimmune disease. Cell Death Different 1999;6:6-12.

56 Nagaraju K, Cox A, Casciola-Rosen L, Rosen A. Novel fragments of the Sjogren's syndrome autoantigens alpha-fodrin and type 3 muscarinic acetylcholine receptor generated during cyłotoxic lymphocyłe granuleinduced cell death. Arthritis Rheum 2001;44:2376-86. 